\title{
Commentary
}

\section{Uteroplacental Blood Flow}

\section{The Story of Decidualization, Menstruation, and Trophoblast Invasion}

\author{
Harvey Jon Kliman \\ From the Department of Obstetrics and Gynecology, Yale \\ University School of Medicine, New Haven, Connecticut
}

Sexual reproduction in the ocean necessitates only the combination of gametes, followed by absorption of nutrients and oxygen from the surrounding watery medium. As life moved from the sea to the land, reproductive strategies required compensation for the loss of this aquatic environment. For mammals and a few other animals, the solution to this problem was the development of the placenta, the means by which the fetus extracts nutrients from its environment. As the animals that used the placenta evolved from small rodent-like creatures with short gestations to larger animals with prolonged gestations, the demands of the developing fetus grew. Whereas the placenta of the fetal pig, with a gestational period of a little less than 4 months, can extract sufficient nutrients from the mother by simple diffusion across the uterus to the placenta, the human fetus needs a far more complex uteroplacental relationship.

Several evolutionary solutions to the increased demands of fetuses can be observed. ${ }^{1}$ One approach was a larger placenta. For example, the chinchilla has a neonatal:placental weight ratio of 30:1, whereas the human has a 6:1 ratio. Another means to greater nutritional support for the fetus was to increase the surface area of contact between fetal circulation in the placenta and maternal circulation. The pig fetus has a diffuse placenta that makes contact with the mother's uterus by a simple folded contact. The human placenta, on the other hand, has a complex villous structure, similar to the sea anemone's tentacles waving in the sea, that greatly increases the contact surface area between the mother's blood space and the fetal circulation. Despite this increased fetal-maternal contact, the system is still rather inefficient. We can quantify this by considering the amount of oxygen in the maternal blood that enters the human placenta and the amount of oxygen in the fetal blood that leaves the placenta. Maternal blood has a $\mathrm{pO}_{2}$ of around 100, whereas the $\mathrm{pO}_{2}$ of umbilical vein blood is around 35 to 40. This represents an efficiency of only 35 to $40 \%$. Therefore, it also became necessary to greatly increase the flow of maternal blood into the intervillous space during pregnancy. ${ }^{2,3}$ Without this increased maternal blood flow, preterm birth and fetal loss occur. ${ }^{4}$ One of two mechanisms can increase maternal flow: increased total body blood flow or increased blood flow to the placental bed through the uterine spiral arteries. For the human, evolution has selected the latter mechanism, limiting the overall systemic effects that increased total body blood flow would produce.

\section{The Nonpregnant State}

In the nonpregnant state the uterine vessels carry $<1 \%$ of the maternal cardiac output. ${ }^{5}$ This is not surprising in light of the fact that a nonpregnant women needs to maintain a uterus that weighs only $50 \mathrm{~g}$. At term, these same vessels must support a uterus, placenta, and fetus that can weigh up to $5000 \mathrm{~g}$. How can these vessels meet such a hemodynamic challenge? Doubling the number of vessels in the uterus, for example, would have only doubled the total amount of flow into the placenta. An understanding of fluid mechanics gives us insight into how such a significant increase in total blood flow can be achieved without increasing the total number of vessels in the uterus.

Poiseuille's law of fluid flow in a cylinder states that flow is proportional to the radius to the fourth power. ${ }^{6}$ Applying this law to the situation in the uterus, doubling the radius of a uterine vessel will increase the flow through that vessel 16 times. Comparison of vessels in the nonpregnant uterus to those at term reveals that these vessels can increase their radii by as much as tenfold. According to Poiseuille's law, this results in an increase in

Accepted for publication September 20, 2000.

Address reprint requests to Harvey Jon Kliman, Department of Obstetrics and Gynecology, Yale University School of Medicine, 333 Cedar Street, New Haven, CT 06520-8063. E-mail: harvey.kliman@yale.edu 
blood flow by a factor of 10,000 ! Clearly, the ability of uterine vessels to vary in diameter is a great advantage. The evolutionary problem then became how to convert small-caliber vessels in the nonpregnant state to largecaliber vessels during pregnancy, and then return them to their nonpregnant state and size when the pregnancy is completed. The answer lies in the relationship between the endometrium, uterine vessels, and invasive trophoblasts.

\section{Invasive Trophoblasts, Decidualization, and Menstruation}

Invasive trophoblasts are the key to the modulation of the state of the uterine vessels. ${ }^{7}$ These unique cells leave the placenta, penetrate the endometrium and upper layers of the myometrium, selectively permeate the uterine spiral arteries, and modify these vessels to yield widened, lowresistance vascular channels that carry the markedly increased maternal blood flow to the placenta. Enacting this scenario takes a very delicate balancing of conflicting biological needs between the mother and fetus. The fetus, on the one hand, requires its invasive trophoblasts to penetrate the mother's uterus aggressively in search of vessels to modify. The mother, on the other hand, must protect herself from the invasive trophoblasts, lest they completely penetrate her uterus, causing her to hemorrhage and bleed to death.

\section{Formation of the Invasive Trophoblasts}

Traditionally, two types of trophoblasts have been described: the cytotrophoblast and the syncytiotrophoblast. With the development of reproducible methods of trophoblast culture, ${ }^{8}$ improved markers of trophoblast synthetic activity, ${ }^{9}$ and a deeper understanding of the functions that trophoblasts play in the uteroplacental unit, ${ }^{10-14}$ we now can identify more specific subsets of trophoblasts. These include the undifferentiated mononuclear precursor of all trophoblast forms, the cytotrophoblast; the endocrinologically active villous syncytiotrophoblast; the junctional trophoblast that attaches the anchoring villi to the maternal decidua at Nitabuch's layer; and the invasive intermediate trophoblast that migrates into the decidua, the myometrium, and finally the spiral arteries of the uterus (Figure 1). ${ }^{15}$

The presence of invasive trophoblasts within the decidua and myometrium has been appreciated for some time ${ }^{16-19}$ but it is only relatively recently that researchers have attributed specific markers, and hence specific functional characteristics, to these cells. The first clear marker of the invasive trophoblast was described by Kurman and colleagues, ${ }^{20}$ who demonstrated that firsttrimester invasive trophoblasts react with anti-human placental lactogen antibodies. They coined the term "intermediate" invasive trophoblasts partly because of their intermediate size between cyto- and syncytiotrophoblasts. Feinberg et $\mathrm{al}^{11}$ demonstrated that these same cells express plasminogen activator inhibitor type 1, suggesting that intermediate invasive trophoblasts may use, in addition to the collagenases, the plasminogen activator system to perform their invasive function. More recently, Zhou et al ${ }^{14,21,22}$ have shown that as trophoblasts leave the cell columns and enter the maternal space, they lose integrins for basement membrane interactions (possibly laminin) and gain integrins for fibronectin and type I collagen interactions.

\section{Decidualization}

To protect the mother from the onslaught of invasive trophoblasts migrating toward the uterine spiral arteries, the endometrial stroma transforms itself into a dense cellular matrix known as the decidua. ${ }^{23}$ The decidua impedes the movement of invasive trophoblasts both by forming a physical barrier to cell penetration and by generating a local cytokine milieu that promotes trophoblast attachment rather than invasion. ${ }^{7,24-28}$ The fate of the invasive trophoblasts is, in part, likely the result of the balancing of the invasive promoting proteases made by the trophoblasts and the inhibitors of invasion made by the decidua. $7,11,29,30$ Fisher and colleagues have recently proposed that local oxygen tension in the decidua and upper myometrium also plays a role in regulating trophoblast invasion by forming a cytotactic gradient within the placental bed. ${ }^{31-33}$ Thus, the ultimate disposition of any particular invasive trophoblast appears to be determined by the sum of the proinvasive factors (intrinsic invasive proteases made by the trophoblasts and the activators and attractants within the decidua) and the inhibitors of invasion (the physical barrier and the inhibitors of invasion made by decidua). ${ }^{7,27,30,34-39}$ Imbalances on either side of this equation can lead to abnormally limited or abnormally excessive invasion. ${ }^{23,26,33,40-43}$

The first signs of the decidualization reaction can be seen as early as day 23 (10 days after the peak of the luteinizing hormone surge) of the normal menstrual cycle, when the spiral arteries of the endometrium first become prominent. ${ }^{44}$ Over the next few days, the stromal cells surrounding the spiral arteries become increasingly eosinophilic and enlarged as the differentiating effect of progesterone transforms these cells into predecidual cells. ${ }^{45}$ The progressive decidualization of the endometrial stroma in the later part of the menstrual cycle prepares the uterine lining for the presence of the invasive trophoblasts, but simultaneously closes the door to implantation. ${ }^{46,47}$ Though the state of the endometrium in the later part of the cycle is ideal to protect the mother from the invasive trophoblasts in the event of a pregnancy, it is entirely unsuited for implantation. But how can a nonreceptive decidualized endometrium be returned to a receptive nondecidualized endometrium if no pregnancy occurs? The solution is menstruation. ${ }^{48-50}$

\section{Menstruation}

Menstruation, the breakdown and sloughing of the endometrial lining at the end of a hormonally driven cycle, is seen only in higher primates and humans ${ }^{48}$ Interestingly, these same species are the only animals that exhibit 


\section{Cytotrophoblast}

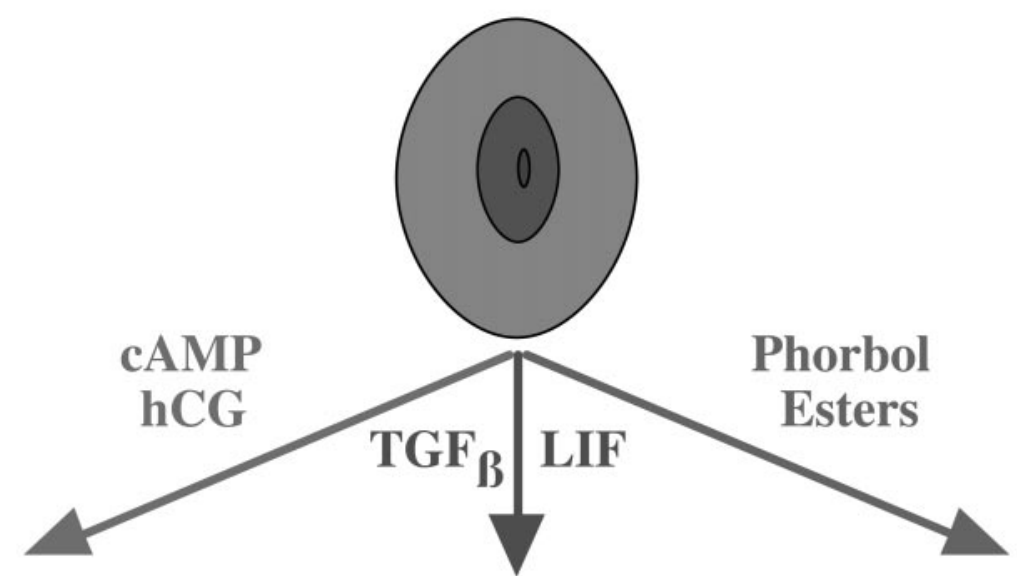

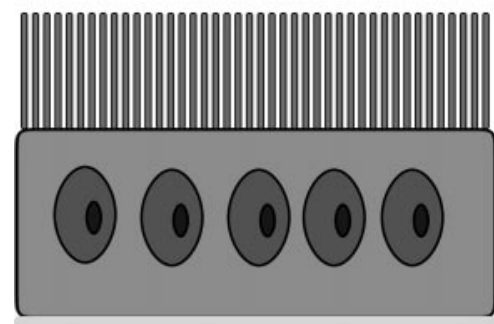

Villous Syncytiotrophoblast

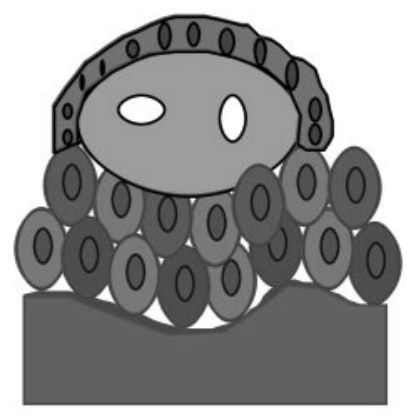

Anchoring Trophoblasts

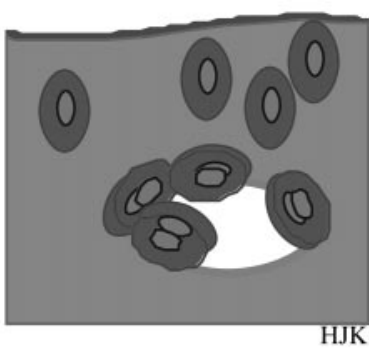

\section{Invading Trophoblasts}

\section{hCG}

TUN

PAI-1

Figure 1. Pathways of trophoblast differentiation. Just as the undifferentiated basal layer of the skin gives rise to differentiated keratinocytes, the cytotrophoblast (the stem cell of the placenta) gives rise to the differentiated forms of trophoblasts. Left: Within the chorionic villi, cytotrophoblasts fuse to form the overlying syncytiotrophoblast. The villous syncytiotrophoblast makes the majority of the placental hormones, the most studied of which is human chorionic gonadotropin (hCG). Cyclic adenosine monophosphate (cAMP) and its analogues, and more recently hCG itself, have been shown to direct cytotrophoblast differentiation toward a hormonally active syncytiotrophoblast phenotype. Center: At the point where chorionic villi make contact with external extracellular matrix (decidual stromal ECM in the case of intrauterine pregnancies), a population of trophoblasts proliferates from the cytotrophoblast layer to form the second type of trophoblast, the junctional trophoblast. The junctional trophoblasts make a unique fibronectin, trophouteronectin (TUN), that appears to mediate the attachment of the placenta to the uterus. Transforming growth factor- $\beta$ (TGF $\beta$ ) and, more recently, leukemia inhibitory factor (LIF) have been shown to down-regulate hCG synthesis and up-regulate TUN secretion. Right: Finally, a third type of trophoblast, the invasive intermediate trophoblast, differentiates toward an invasive phenotype and leaves the placenta entirely. In addition to making human placental lactogen, these cells also make urokinase-type plasminogen activator and type 1 plasminogen activator inhibitor (PAI-1). Phorbol esters have been shown to increase trophoblast invasiveness in in vitro model systems and to up-regulate PAI- 1 in cultured trophoblasts.

evidence of trophoblast invasion of uterine vessels, supporting the contention that menstruation is a biological necessity in species that exhibit trophoblast invasion. Thus, it appears that menstruation is the mechanism by which the endometrium reestablishes a receptive phase following a cycle without conception. This would help to explain the complex nature of the menstrual cycle with an estrogen-driven proliferative phase (to rebuild the lost endometrial tissue) followed by a progesterone-driven differentiation phase (that first opens the window of receptivity and later closes this window with the onset of decidualization). ${ }^{51,52}$

\section{Trophoblast Invasion}

\section{Anatomy of Trophoblast Invasion}

The morphological aspects of human trophoblast invasion have been examined in great detail over the last 20 years. ${ }^{11,17,31,39,43,53-58}$ Since it is difficult to reliably obtain human material before 4 weeks of gestation, much of our morphological understanding of the earliest phases of trophoblast invasion has been extrapolated from monkey material. ${ }^{59-62}$ Examination of monkey implantation sites has revealed that trophoblasts begin to migrate down into the maternal spiral arteries as early as 10 days 
after fertilization, and at 14 days, many of the spiral arteries beneath the conceptus are totally occluded. ${ }^{62}$ The specificity of this vascular interaction is revealed by the fact that no such invasion takes place in the veins. Do human trophoblasts behave in the same fashion? This question has been more difficult to answer, and addressing it has demanded varied approaches.

Hustin and Schaaps, using anatomical and ultrasonographic approaches, suggested that there is in fact trophoblast plugging of the maternal spiral arteries and a coincident decrease in maternal perfusion of intervillous space until 12 weeks of gestation. ${ }^{63}$ Rodesch et al ${ }^{64}$ then hypothesized that it is critical that maternal blood flow to the embryo be limited very early in gestation to protect the conceptus from excessively high oxygen levels during critical early stages of differentiation. This concept was supported by Coppens et al, ${ }^{65}$ whose study of serial ultrasounds on normal pregnant women between 8 and 14 weeks showed no uteroplacental blood flow in the first trimester but a significant increase at approximately 12 weeks, which reached maximal levels at 14 weeks. More recently, Burton et al critically examined the Boyd Collection, 12 early-pregnancy hysterectomy specimens ranging from 43 to 130 days of gestation housed in the Department of Anatomy at the University of Cambridge, and showed that there was significant blockage of the maternal spiral arterioles by trophoblasts at points of contact with the intervillous space between 6 and 8 weeks, but that this blockage was gradually eliminated between 8 and 12 weeks of gestation. ${ }^{66}$

Despite its teleological attractiveness, the first trimester low-flow concept has not been universally accepted. ${ }^{67-69}$ The controversy over this issue, however, seems to have been settled recently with the use of an advanced oxygen sensing probe. In this issue of The American Journal of Pathology, Jauniaux et $\mathrm{al}^{70}$ report the direct documentation of a significant increase in placental intervillous oxygen tension, and hence maternal perfusion of the placenta, between 8 and 12 weeks of gestation. This article also reports that, coincident with this increased perfusion and oxygen tension within the placenta between 8 and 12 weeks, there is a corresponding increase in anti-oxidant systems, including catalase, glutathione peroxidase, and superoxide dismutase, presumably to counteract the oxidative stress of the increased intervillous perfusion and oxygen tension. If we accept trophoblast plugging and the first trimester low-flow concept, one question remains: how are the first-trimester embryo's nutritional needs met? Hustin and Schaaps suggested that the intervillous space is bathed by an acellular fluid that could be plasma filtered by the trophoblastic shell. ${ }^{63}$ Burton and colleagues have offered another possibility (Burton GJ, Watson AL, Hempstock J, Skepper JN, Jauniaux E, submitted). By examining multiple human implantation sites preserved in the Boyd Collection, ${ }^{66}$ these investigators noted the presence of dilated endometrial glands below openings to the intervillous spaces. It is well known that the endometrial glands of early pregnancy are characterized by hypersecretion. ${ }^{71}$ Combining these observations, Burton and colleagues have suggested that secretions from the hy-

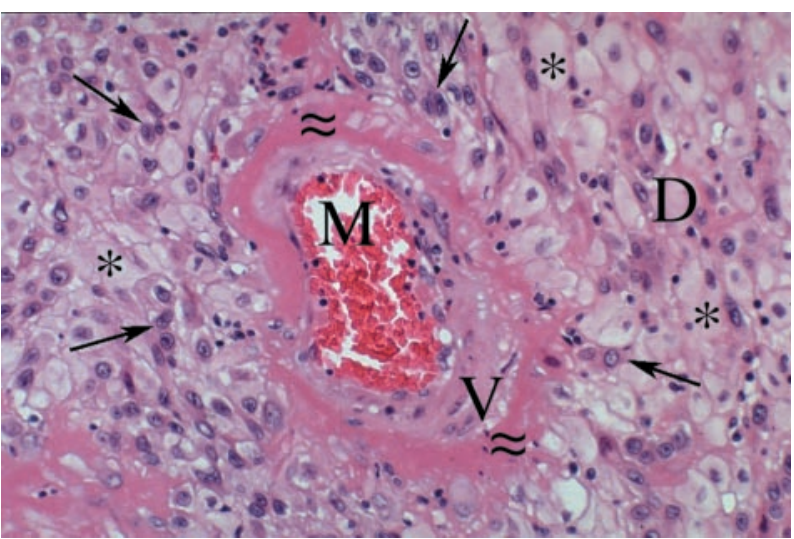

Figure 2. Invasive trophoblasts. Uterine spiral artery (V) containing maternal blood (M) from a 4-week pregnancy. The maternal endometrium (D) has become decidualized, meaning that the stromal cells have been transformed into large, pale cells (*). Infiltrating between these decidual cells are the invasive trophoblasts (some examples are highlighted by arrows) which have begun to modify the vessel wall $(\approx)$.

persecretory endometrial glands contribute nutrients to the embryo in the first trimester. In confirmation of this hypothesis, these workers noted in several specimens glandular secretions within the intervillous spaces near the openings of the gland mouths. Their hypothesis is not unreasonable in light of the fact that other animals, most notably the rabbit and pig, bathe their early conceptuses in endometrium-derived fluids, such as uteroglobin, ${ }^{72-74}$ which has also been recently identified in the human. ${ }^{75}$

Concomitant with endovascular plugging of the maternal spiral arteries, the process of trophoblast penetration of the maternal spiral arteries and their conversion to low-resistance channels begins (Figure 2). Pijnenborg and colleagues, after examination of many placental bed biopsies from the first and second trimesters, proposed a two-wave hypothesis for trophoblast invasion: an initial interstitial invasion in the first trimester followed by endovascular invasion in the second trimester. ${ }^{17,18,76,77}$ Matijevic et al, ${ }^{78}$ using transabdominal color flow and pulsed Doppler imaging, showed that these changes were complete at around 17 weeks of gestation and that impedance to blood flow is lowest in the uterine arteries in the central area of the placental bed, consistent with the invasive trophoblast physiological changes seen in placental bed biopsies in that region. ${ }^{18}$ Pijnenborg also made the observation in his studies that the interstitial trophoblasts were able to modify the maternal arteries indirectly, presumably via paracrine action, simply by surrounding these vessels. ${ }^{18}$ One possible mediator of this action is nitric oxide (NO), which is capable of markedly vasodilating arteries and arterioles. In support of this concept, Nanaev et al, ${ }^{79}$ from examination of the guinea pig placental bed, have suggested that NO production by invasive trophoblasts may augment maternal vascular dilation before trophoblast penetration. However, Lyall et $\mathrm{al}^{57}$ have recently demonstrated in the human that invasive trophoblasts do not express NO synthase, raising doubts about the role of $\mathrm{NO}$ in maternal vascular dilation in the human. Further research will be necessary to iden- 
tify what other paracrine factors, if any, may assist in the modification of the maternal spiral arteries.

Not all investigators concur on the role of invasive trophoblasts in maternal vascular remodeling. Craven et al have proposed that the maternal decidua, not the invasive trophoblasts, mediates this transformation. ${ }^{80}$ However, given the voluminous literature supporting the role of invasive trophoblasts as the mediators of maternal vascular transformation in pregnancy, validation of the Craven hypothesis must await further observation. Despite the unresolved issues surrounding our understanding of the anatomy of trophoblast invasion, it is still far better than our understanding of the mechanisms that regulate trophoblast invasion. ${ }^{17,18,76,77}$

\section{Regulation of Trophoblast Invasion}

The precise mechanisms by which trophoblasts migrate from the placenta into the uterus, direct their movement toward the maternal spiral arteries, modify these vessels to form the low resistance channels needed to carry the increased maternal blood flow to the placenta, limit their invasion to the upper third of the uterus, and finally are eliminated after delivery are not known. However, some pieces of this story are understood, and, with increased investigation, we continue to make progress in this area. ${ }^{7,30,81}$ Because trophoblast invasion appears to involve many steps, it is not surprising that trophoblasts use a variety of tools to perform these many functions.

The first challenge for the trophoblasts is to alter their differentiation pathway from that of a villous trophoblast to an anchoring trophoblast. ${ }^{7,15}$ This process occurs, in part, due to contact of trophoblasts with the decidua, via either paracrine stimulation or direct contact with the decidual extracellular matrix (ECM). Vicovac et al have recently shown that villi incubated in direct contact with decidua form cell columns, suggesting that signals in the decidual ECM play a role in this differentiation switching, ${ }^{82}$ although these studies do not rule out a diffusible paracrine. In fact, there is clear evidence for the presence of decidual cytokines that have a profound effect on trophoblast differentiation. ${ }^{7,9}$ For example, transforming growth factor- $\beta$ is not only made by the decidua, ${ }^{25,83}$ it has also been shown to alter trophoblast differentiation toward an anchoring phenotype. 9,15,84 Leukemia inhibitory factor, an endometrial cytokine that has been shown to be essential for mouse implantation, ${ }^{85,86}$ has also been identified in human endometrium ${ }^{87,88}$ and has also been shown to alter trophoblast differentiation from a villous to an anchoring phenotype (Figure 1). ${ }^{89}$

Although markers of invasive trophoblasts have been described, ${ }^{11,20,37,90}$ the factors that direct trophoblast differentiation toward an invasive phenotype have not been established. Suggested regulators of trophoblast invasion include epidermal growth factor, ${ }^{36}$ colony stimulating factor-1, ${ }^{91,92}$ protein kinase $\mathrm{C}$ activators, ${ }^{93}$ hepatocyte growth factor, ${ }^{94}$ and even oxygen. ${ }^{31-33}$

\section{Uteroplacental Blood Flow in Pregnancy}

\section{Measurement of Blood Flow in Pregnancy}

The action of the invasive trophoblasts on the maternal spiral arteries leads to a very low resistance uteroplacental circulation, which facilitates the marked increase in blood flow seen in these vessels at term. Using a variety of techniques, many groups have estimated the amount of blood flow into the gravid uterus. ${ }^{95-99}$ This work has demonstrated that at term a woman's total blood volume increases by about $40 \%$ compared to her nonpregnant state. ${ }^{100}$ Concomitantly, her cardiac output rises 30 to $35 \%$ and the total uteroplacental blood flow increases to about $25 \%$ of her total cardiac output. ${ }^{101,102}$ Direct measurements of uterine blood flow in the nonpregnant state have shown a combined uterine artery flow in the follicular phase to be approximately $45 \mathrm{ml} /$ minute $^{103}$ whereas the total uterine flow at term has been estimated to be as high as $750 \mathrm{ml} / \mathrm{minute}{ }^{96}$ representing an almost 17 -fold increase in flow to the uterus. Improvements in techniques to estimate blood flow in the gravid uterus have suggested that this last calculation may be too high. Thaler et al ${ }^{99}$ used a transvaginal duplex Doppler ultrasonography system to compare the blood flow characteristics in the ascending uterine artery before and during pregnancy in the same patient and determined that there was a 3.5-fold increase in blood flow, still a significant increase in total blood flow to the gravid uterus.

\section{Regulation of Maternal Blood Flow to the Placenta}

As Jauniaux et $\mathrm{al}^{70}$ have shown in this issue of The American Journal of Pathology, maternal blood flow to the placenta appears to be restricted in the first trimester, but begins to increase in earnest at approximately 12 weeks of gestation. Beyond this jump in uteroplacental blood flow, is there evidence of additional modulation of maternal perfusion of the placenta? Studies have shown that a number of exogenous factors can modulate maternal perfusion to the placenta, but little is known about how, if at all, the uteroplacental circulation is regulated in normal pregnancy.

A significant amount of our understanding of what factors are able to alter uteroplacental blood flow comes from in vitro studies of isolated maternal uterine arteries and arterioles. Hansen et $\mathrm{al}^{104}$ showed that vasoactive intestinal polypeptide and substance $P$ are capable of dilating isolated uterine arteries. Skajaa et al ${ }^{105}$ demonstrated the ability of $\mathrm{Mg}^{2+}$ ions to relax uterine arteries, confirming experimentally what has been known for many years about magnesium sulfate's efficacy in the treatment of preeclampsia. ${ }^{106}$ Endothelin 1 and endothelin 3 were shown to be potent vasoconstrictors of uterine arteries. ${ }^{107}$ Fried and Liu ${ }^{108}$ confirmed endothelin's action on isolated uterine arteries and demonstrated an inhibition of $\sim 60 \%$ of this effect with the addition of nifedipine and diltiazem, both calcium channel blockers. Kublickiene et $\mathrm{al}^{109}$ showed a similar in vitro effect of isradipine on endothelin-induced uterine vessel vasoconstriction. Re- 
laxin, another vasodilator, however, was shown not to be effective in dilating isolated uterine vessels in vitro. ${ }^{110}$

Other investigators have looked directly at the uteroplacental circulation to assess the role of pharmacological agents. For example, Neri et al ${ }^{111}$ infused L-arginine, the substrate for NO, intravenously into pregnant women, assessed uteroplacental vessel pulsatile index by ultrasound, and showed a $14 \%$ decrease in vascular resistance in women with pre-existing intrauterine growth retardation. Using an oral route, Amit et al ${ }^{112}$ showed that isosorbide dinitrate, a NO donor, had a significant effect on the resistance index in the uterine artery, independent of maternal heart rate. Low-dose aspirin, though it does not appear to alter uteroplacental blood flow, ${ }^{113}$ may nevertheless have some benefit for patients with preeclampsia. ${ }^{114}$

Not all pharmacological agents are prescribed. Nicotine exposure through smoking has a significant vasoconstrictive effect on uterine vessels, ${ }^{115,116}$ causing decreased perfusion while the mother is smoking and for 15 minutes after the completion of a cigarette. ${ }^{117}$ Cocaine, a well known vasoconstrictor in other organ systems, ${ }^{118,119}$ has profound effects on the uteroplacental circulation, ${ }^{120}$ possibly through increased production of thromboxane. ${ }^{121}$ The vasoconstrictive effect of cocaine can be so potent that it can cause severe intrauterine fetal damage and death due to a profound decrease in uteroplacental blood flow. ${ }^{122-126}$

In a holistic approach, Longo has looked at uteroplacental blood flow in the context of the whole pregnant patient. ${ }^{127} \mathrm{He}$ has proposed that there exists a feedback loop between the developing fetus, placenta, and mother, mediated by fetal steroids, that regulates the maternal cardiovascular adaptations seen in pregnancy to optimize fetal growth and development. Abnormalities in this complex network of hormonal regulation may contribute to poor fetal outcome.

\section{Preeclampsia: Pathology of Trophoblast Invasion}

Preeclampsia, the clinical state before full-blown eclampsia (seizures), is one of the toxemias of pregnancy. Its basic clinical definition is a "pregnancy-specific condition of increased blood pressure accompanied by proteinuria, edema, or both." ${ }^{106}$ Despite the simplicity of this description of clinical signs and symptoms, the etiology of the disease has remained elusive. ${ }^{22,56,128-145}$ Many phenomena have been investigated, but the recurring theme appears to be an abnormally low blood flow into the placenta. ${ }^{19,141}$ One of the difficulties has been to distinguish between primary cause and secondary effects. ${ }^{130-135,138,146}$ Part of this difficulty may be attributable to the fact that the common end result, low uteroplacental blood flow, may be caused by many primary defects. ${ }^{14,22,42,147-149}$ Therefore, preeclampsia/eclampsia may not be a disease, but a syndrome with many causes. Significantly, one of the most frequent findings in preeclampsia is decreased or absent trophoblast invasion of the maternal spiral arteries. ${ }^{19,56,150-153}$

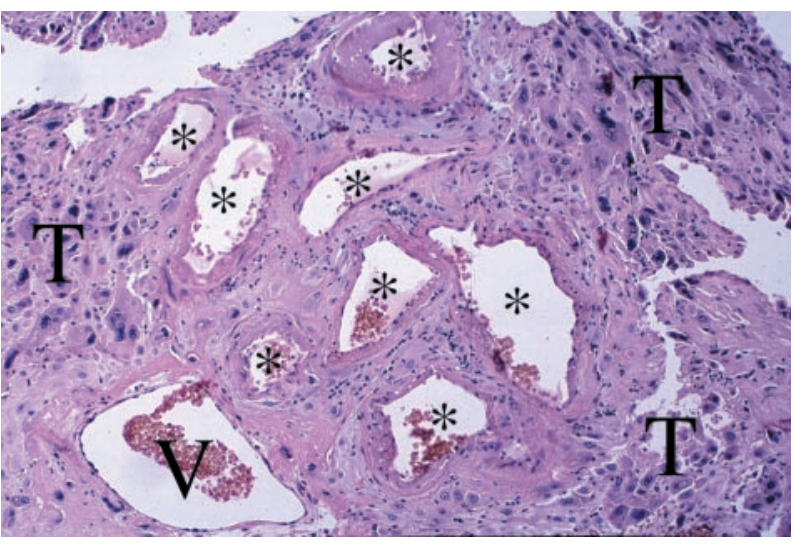

Figure 3. Failure of invasive trophoblasts to penetrate the maternal spiral arteries. Normally the invasive trophoblasts (T) infiltrate through the endoand myometrium, reach the spiral arteries $(*)$, and convert their muscular walls into pliant channels. In cases of preeclampsia, the trophoblasts often do not complete the final arterial penetration, possibly due to the maternal lymphocytes that commonly surround the spiral arteries. Compensatory maternal hypertension can lead to additional spiral artery damage or even occlusion. V, maternal uterine vein.

Decreased or absent trophoblast invasion may be a consequence of primary defects in the invasive trophoblasts or in the environment that the trophoblasts are attempting to invade. Studies have shown that in some cases of preeclampsia there are abnormalities in trophoblast function, including but not limited to integrin expression, ${ }^{22,58}$ thrombomodulin gene expression, ${ }^{154}$ glycogen metabolism, ${ }^{155}$ decreased galactose- $\alpha-1-3$ galactose expression, ${ }^{156}$ and expression of plasminogen activator inhibitor-1. ${ }^{157}$ In an unusual clinical presentation, preeclampsia has been associated with trisomy 13 , the chromosome that carries the gene for type IV collagen. ${ }^{147}$ Placental bed biopsy in this multiparous woman carrying a trisomy 13 fetus showed lack of trophoblast invasion of maternal spiral arteries. ${ }^{147}$ These trophoblasts may have had difficulty invading through the maternal ECM because of increased type IV collagen production. In addition to primary trophoblast defects, many cases of preeclampsia appear to be related to maternal immunological reaction against the invading trophoblasts. ${ }^{128,134}$ Some authors have suggested that the invasive trophoblasts exhibit "shallow invasion" in cases of preeclampsia. ${ }^{42,135}$ However, this finding is not confirmed by clinical observation. The most common clinical finding in cases of preeclampsia is that the invasive trophoblasts have reached the vicinity of the spiral arteries, but have not penetrated them, ${ }^{7,15,19}$ as can be seen from a placental bed biopsy in a typical case of preeclampsia (Figure 3). Failure to convert the maternal spiral arteries into low-resistance channels can induce the placenta to secrete vasoactive substances that result in maternal hypertension. ${ }^{146,158}$ If the maternal blood pressure rises significantly, the spiral arteries can be damaged and may even become occluded, leading to placental infarction. ${ }^{4,141,159}$ 


\section{Acknowledgments}

I thank Juliette C. McSweet and Gabrielle E. Brainard for assistance in the preparation and Bernice W. Kliman in the editing of this Commentary.

\section{References}

1. Benirschke K, Kaufmann P: Pathology of the Human Placenta, 3d edition. New York, Springer-Verlag, 1995

2. Thornburg KL, Jacobson SL, Giraud GD, Morton MJ: Hemodynamic changes in pregnancy. Semin Perinatol 2000, 24:11-14

3. Duvekot JJ, Peeters LL: Maternal cardiovascular hemodynamic adaptation to pregnancy. Obstet Gynecol Surv 1994, 49:S1-S14

4. Naeye RL: Pregnancy hypertension, placental evidences of low uteroplacental blood flow, and spontaneous premature delivery. Hum Pathol 1989, 20:441-444

5. Silver M, Barnes RJ, Comline RS, Burton GJ: Placental blood flow: some fetal and maternal cardiovascular adjustments during gestation. J Reprod Fertil Suppl 1982, 31:139-160

6. Poston L: The control of blood flow to the placenta. Exp Physiol 1997, 82:377-387

7. Kliman HJ: Trophoblast infiltration. Reprod Med Rev 1994, 3:137157

8. Kliman HJ, Nestler JE, Sermasi E, Sanger JM, Strauss JF: Purification, characterization, and in vitro differentiation of cytotrophoblasts from human term placentae. Endocrinology 1986, 118:1567-1582

9. Kliman HJ, Feinberg RF: Trophoblast differentiation. The First Twelve Weeks of Gestation. Edited by Barnea E, Hustin J, Jauniaux E. New York, Springer-Verlag, 1992, pp 3-25

10. Feinberg RF, Kliman HJ, Lockwood CJ: Oncofetal fibronectin: a trophoblast "glue" for human implantation? Am J Pathol 1991, 138: 537-543

11. Feinberg RF, Kao LC, Haimowitz JE, Queenan JT Jr, Wun TC Strauss JF, Kliman HJ: Plasminogen activator inhibitor types 1 and 2 in human trophoblasts: PAI-1 is an immunocytochemical marker of invading trophoblasts. Lab Invest 1989, 61:20-26

12. Damsky $\mathrm{CH}$, Fitzgerald ML, Fisher SJ: Distribution patterns of extracellular matrix components and adhesion receptors are intricately modulated during first trimester cytotrophoblast differentiation along the invasive pathway, in vivo. J Clin Invest 1992, 89:210-222

13. Fernandez PL, Merino MJ, Nogales FF, Charonis AS, Stetler Stevenson W, Liotta L: Immunohistochemical profile of basement membrane proteins and 72 kilodalton type IV collagenase in the implantation placental site: an integrated view. Lab Invest 1992, 66:572579

14. Zhou Y, Damsky CH, Chiu K, Roberts JM, Fisher SJ: Preeclampsia is associated with abnormal expression of adhesion molecules by invasive cytotrophoblasts. J Clin Invest 1993, 91:950-960

15. Kliman HJ: Trophoblast to human placenta. Encyclopedia of Reproduction, vol 4. Edited by Knobil E, Neill JD. San Diego, Academic Press, 1999, pp 834-846

16. Pijnenborg R, Robertson WB, Brosens I, Dixon G: Review article: trophoblast invasion and the establishment of haemochorial placentation in man and laboratory animals. Placenta 1981, 2:71-91

17. Pijnenborg R, Bland JM, Robertson WB, Brosens I: Uteroplacental arterial changes related to interstitial trophoblast migration in early human pregnancy. Placenta 1983, 4:397-413

18. Pijnenborg R: The placentae bed. Hypertens Preg 1996, 15:7-23

19. Pijnenborg R, Vercruysse L, Verbist L, Van Assche FA: Interaction of interstitial trophoblast with placental bed capillaries and venules of normotensive and pre-eclamptic pregnancies. Placenta 1998, 19: $569-575$

20. Kurman RJ, Main CS, Chen HC: Intermediate trophoblast: a distinctive form of trophoblast with specific morphological, biochemical and functional features. Placenta 1984, 5:349-369

21. Zhou Y, Fisher SJ, Janatpour M, Genbacev O, Dejana E, Wheelock $\mathrm{M}$, Damsky $\mathrm{CH}$ : Human cytotrophoblasts adopt a vascular phenotype as they differentiate: a strategy for successful endovascular invasion? J Clin Invest 1997, 99:2139-2151

22. Zhou Y, Damsky CH, Fisher SJ: Preeclampsia is associated with failure of human cytotrophoblasts to mimic a vascular adhesion phenotype: one cause of defective endovascular invasion in this syndrome? J Clin Invest 1997, 99:2152-2164

23. Kearns M, Lala PK: Life history of decidual cells: a review. Am J Reprod Immunol 1983, 3:78-82

24. Graham $\mathrm{CH}$, Lala PK: Mechanisms of placental invasion of the uterus and their control. Biochem Cell Biol 1992, 70:867-874

25. Graham CH, Lysiak JJ, McCrae KR, Lala PK: Localization of transforming growth factor-beta at the human fetal-maternal interface: role in trophoblast growth and differentiation. Biol Reprod 1992 46:561-572

26. Clark DA: Cytokines, decidua, and early pregnancy. Oxf Rev Reprod Biol 1993, 15:83-111

27. Roth I, Fisher SJ: IL-10 is an autocrine inhibitor of human placental cytotrophoblast MMP-9 production and invasion. Dev Biol 1999, 205:194-204

28. Tabibzadeh S, Lessey B, Satyaswaroop PG: Temporal and sitespecific expression of transforming growth factor-beta4 in human endometrium. Mol Hum Reprod 1998, 4:595-602

29. Graham $\mathrm{CH}$, Lala PK: Mechanism of control of trophoblast invasion in situ. J Cell Physiol 1991, 148:228-234

30. Strickland S, Richards WG: Invasion of the trophoblasts. Cell 1992 71:355-357

31. Zhou Y, Genbacev O, Damsky CH, Fisher SJ: Oxygen regulates human cytotrophoblast differentiation and invasion: implications for endovascular invasion in normal pregnancy and in pre-eclampsia. $J$ Reprod Immunol 1998, 39:197-213

32. Genbacev O, Zhou Y, Ludlow JW, Fisher SJ: Regulation of human placental development by oxygen tension. Science 1997, 277 1669-1672

33. Zhou Y, Chiu K, Brescia RJ, Combs CA, Katz MA, Kitzmiller JL, Heilbron DC, Fisher SJ: Increased depth of trophoblast invasion after chronic constriction of the lower aorta in rhesus monkeys. Am J Obstet Gynecol 1993, 169:224-229

34. Bischof P, Friedli E, Martelli M, Campana A: Expression of extracellular matrix-degrading metalloproteinases by cultured human cytotrophoblast cells: effects of cell adhesion and immunopurification Am J Obstet Gynecol 1991, 165:1791-1801

35. Fisher SJ, Damsky CH: Human cytotrophoblast invasion. Semin Cell Biol 1993, 4:183-188

36. Bass KE, Morrish D, Roth I, Bhardwaj D, Taylor R, Zhou Y, Fisher SJ: Human cytotrophoblast invasion is up-regulated by epiderma growth factor: evidence that paracrine factors modify this process. Dev Biol 1994, 164:550-561

37. Damsky $\mathrm{CH}$, Librach C, Lim KH, Fitzgerald ML, McMaster MT Janatpour M, Zhou Y, Logan SK, Fisher SJ: Integrin switching regulates normal trophoblast invasion. Development 1994, 120:36573666

38. Bischof P, Haenggeli L, Campana A: Gelatinase and oncofetal fibronectin secretion is dependent on integrin expression on human cytotrophoblasts. Hum Reprod 1995, 10:734-742

39. Huppertz B, Kertschanska S, Demir AY, Frank HG, Kaufmann P Immunohistochemistry of matrix metalloproteinases (MMP), their substrates, and their inhibitors (TIMP) during trophoblast invasion in the human placenta. Cell Tissue Res 1998, 291:133-148

40. Lala PK, Kearns M: Immunobiology of the decidual tissue. Contrib Gynecol Obstet 1985, 14:1-15

41. Genbacev O, Bass KE, Joslin RJ, Fisher SJ: Maternal smoking inhibits early human cytotrophoblast differentiation. Reprod Toxicol 1995, 9:245-255

42. DiFederico E, Genbacev O, Fisher SJ: Preeclampsia is associated with widespread apoptosis of placental cytotrophoblasts within the uterine wall. Am J Pathol 1999, 155:293-301

43. Genbacev O, DiFederico E, McMaster M, Fisher SJ: Invasive cytotrophoblast apoptosis in pre-eclampsia. Hum Reprod 1999, 14 59-66

44. Hendrickson MR, Kempson RL: Surgical pathology of the uterine corpus. Major Probl Pathol 1979, 12:36-98

45. Tabanelli S, Tang B, Gurpide E: In vitro decidualization of human endometrial stromal cells. J Steroid Biochem Mol Biol 1992, 42:337344

46. Lessey BA, Castelbaum AJ, Buck CA, Lei Y, Yowell CW, Sun J: Further characterization of endometrial integrins during the menstrual cycle and in pregnancy. Fertil Steril 1994, 62:497-506 
47. Lessey BA: The use of integrins for the assessment of uterine receptivity. Fertil Steril 1994, 61:812-814

48. Finn CA: Why do women menstruate? Historical and evolutionary review. Eur J Obstet Gynecol Reprod Biol 1996, 70:3-8

49. Strassmann BI: The evolution of endometrial cycles and menstruation. Q Rev Biol 1996, 71:181-220

50. Finn CA: Menstruation: a nonadaptive consequence of uterine evolution. Q Rev Biol 1998, 73:163-173

51. Espey LL, Ben Halim IA: Characteristics and control of the normal menstrual cycle. Obstet Gynecol Clin North Am 1990, 17:275-298

52. Chabbert Buffet N, Djakoure C, Maitre SC, Bouchard P: Regulation of the human menstrual cycle. Front Neuroendocrinol 1998, 19:151186

53. Pijnenborg R, Bland JM, Robertson WB, Dixon G, Brosens I: The pattern of interstitial trophoblastic invasion of the myometrium in early human pregnancy. Placenta 1981, 2:303-316

54. Pijnenborg R, Robertson WB, Brosens I: Trophoblast invasion and formation of the basal plate in the human placenta. Bibl Anat 1982, 22:69-73

55. Robertson WB, Brosens I, Pijnenborg R, De Wolf F: The making of the placental bed. Eur J Obstet Gynecol Reprod Biol 1984, 18:255266

56. Robertson WB, Brosens I, Landells WN: Abnormal placentation. Obstet Gynecol Annu 1985, 14:411-426

57. Lyall F, Bulmer JN, Kelly H, Duffie E, Robson SC: Human trophoblast invasion and spiral artery transformation: the role of nitric oxide. Am J Pathol 1999, 154:1105-1114

58. Lim KH, Zhou Y, Janatpour M, McMaster M, Bass K, Chun SH, Fisher SJ: Human cytotrophoblast differentiation/invasion is abnormal in pre-eclampsia. Am J Pathol 1997, 151:1809-1818

59. Blankenship TN, Enders AC, King BF: Trophoblastic invasion and the development of uteroplacental arteries in the macaque: immunohistochemical localization of cytokeratins, desmin, type IV collagen, laminin, and fibronectin. Cell Tissue Res 1993, 272:227-236

60. Blankenship TN, Enders AC, King BF: Trophoblastic invasion and modification of uterine veins during placental development in macaques. Cell Tissue Res 1993, 274:135-144

61. Enders AC, Welsh AO: Structural interactions of trophoblast and uterus during hemochorial placenta formation. J Exp Zool 1993, 266:578-587

62. Enders AC, King BF: Early stages of trophoblastic invasion of the maternal vascular system during implantation in the macaque and baboon. Am J Anat 1991, 192:329-346

63. Hustin J, Schaaps JP: Echographic and anatomic studies of the maternotrophoblastic border during the first trimester of pregnancy. Am J Obstet Gynecol 1987, 157:162-168

64. Rodesch F, Simon P, Donner C, Jauniaux E: Oxygen measurements in endometrial and trophoblastic tissues during early pregnancy. Obstet Gynecol 1992, 80:283-285

65. Coppens M, Loquet P, Kollen M, De Neubourg F, Buytaert P: Longitudinal evaluation of uteroplacental and umbilical blood flow changes in normal early pregnancy. Ultrasound Obstet Gynecol 1996, 7:114-121

66. Burton GJ, Jauniaux E, Watson AL: Maternal arterial connections to the placental intervillous space during the first trimester of human pregnancy: the Boyd collection revisited. Am J Obstet Gynecol 1999, 181:718-724

67. Kurjak A, Kupesic S, Hafner T, Kos M, Kostovic-Knezevic L, Grbesa D: Conflicting data on intervillous circulation in early pregnancy. $J$ Perinat Med 1997, 25:225-236

68. Valentin L, Sladkevicius P, Laurini R, Soderberg H, Marsal K: Uteroplacental and luteal circulation in normal first-trimester pregnancies: Doppler ultrasonographic and morphologic study. Am J Obstet Gynecol 1996, 174:768-775

69. Moll W: Invited commentary: absence of intervillous blood flow in the first trimester of human pregnancy. Placenta 1995, 16:333-334

70. Jauniaux E, Watson AL, Hempstock J, Bao Y-P, Skepper JN, Burton GJ: Onset of maternal arterial bloodflow and placental oxidative stress: a possible factor in human early pregnancy failure. Am $\mathrm{J}$ Pathol 2000, 157:3251-3262

71. Arias-Stella $\mathrm{J} J \mathrm{r}$, Arias-Velasquez A, Arias-Stella J: Normal and abnormal mitoses in the atypical endometrial change associated with chorionic tissue effect. Am J Surg Pathol 1994, 18:694-701
72. Bazer FW: Uterine protein secretions: relationship to development of the conceptus. J Anim Sci 1975, 41:1376-1382

73. Beier HM: Uteroglobin and related biochemical changes in the reproductive tract during early pregnancy in the rabbit. J Reprod Fertil Suppl 1976, pp 53-69

74. Basha SM, Bazer FW, Geisert RD, Roberts RM: Progesterone-induced uterine secretions in pigs: recovery from pseudopregnant and unilaterally pregnant gilts. J Anim Sci 1980, 50:113-123

75. Muller-Schottle F, Classen-Linke I, Alfer J, Krusche C, Beier-Hellwig $\mathrm{K}$, Sterzik K, Beier HM: Expression of uteroglobin in the human endometrium. Mol Hum Reprod 1999, 5:1155-1161

76. Pijnenborg R: Establishment of uteroplacental circulation. Reprod Nutr Dev 1988, 28:1581-1586

77. Pijnenborg R, Dixon G, Robertson WB, Brosens I: Trophoblastic invasion of human decidua from 8 to 18 weeks of pregnancy. Placenta 1980, 1:3-19

78. Matijevic R, Meekins JW, Walkinshaw SA, Neilson JP, McFadyen IR: Spiral artery blood flow in the central and peripheral areas of the placental bed in the second trimester. Obstet Gynecol 1995, 86 : 289-292

79. Nanaev A, Chwalisz K, Frank HG, Kohnen G, Hegele-Hartung C Kaufmann P: Physiological dilation of uteroplacental arteries in the guinea pig depends on nitric oxide synthase activity of extravillous trophoblast. Cell Tissue Res 1995, 282:407-421

80. Craven CM, Morgan T, Ward K: Decidual spiral artery remodelling begins before cellular interaction with cytotrophoblasts. Placenta $1998,19: 241-252$

81. Cross JC, Werb Z, Fisher SJ: Implantation and the placenta: key pieces of the development puzzle. Science 1994, 266:1508-1518

82. Vicovac L, Jones CJ, Aplin JD: Trophoblast differentiation during formation of anchoring villi in a model of the early human placenta in vitro. Placenta 1995, 16:41-56

83. Hofmann GE, Horowitz GM, Scott RT Jr, Navot D: Transforming growth factor-alpha in human implantation trophoblast: immunohistochemical evidence for autocrine/paracrine function. J Clin Endocrinol Metab 1993, 76:781-785

84. Feinberg RF, Kliman HJ, Wang CL: Transforming growth factor-beta stimulates trophoblast oncofetal fibronectin synthesis in vitro: implications for trophoblast implantation in vivo. J Clin Endocrinol Metab 1994, 78:1241-1248

85. Stewart CL, Kaspar P, Brunet LJ, Bhatt H, Gadi I, Kontgen F, Abbondanzo SJ: Blastocyst implantation depends on maternal expression of leukaemia inhibitory factor. Nature 1992, 359:76-79

86. Bhatt $\mathrm{H}$, Brunet LJ, Stewart CL: Uterine expression of leukemia inhibitory factor coincides with the onset of blastocyst implantation. Proc Natl Acad Sci USA 1991, 88:11408-11412

87. Arici A, Engin O, Attar E, Olive DL: Modulation of leukemia inhibitory factor gene expression and protein biosynthesis in human endometrium. J Clin Endocrinol Metab 1995, 80:1908-1915

88. Cullinan EB, Abbondanzo SJ, Anderson PS, Pollard JW, Lessey BA Stewart CL: Leukemia inhibitory factor (LIF) and LIF receptor expression in human endometrium suggests a potential autocrine/paracrine function in regulating embryo implantation. Proc Natl Acad Sci USA 1996, 93:3115-3120

89. Nachtigall MJ, Kliman HJ, Feinberg RF, Olive DL, Engin O, Arici A The effect of leukemia inhibitory factor (LIF) on trophoblast differentiation: a potential role in human implantation. $J$ Clin Endocrinol Metab 1996, 81:801-806

90. McMaster MT, Librach CL, Zhou Y, Lim KH, Janatpour MJ, DeMars R, Kovats S, Damsky C, Fisher SJ: Human placental HLA-G expression is restricted to differentiated cytotrophoblasts. J Immunol 1995 154:3771-3778

91. Jokhi PP, Chumbley G, King A, Gardner L, Loke YW: Expression of the colony stimulating factor- 1 receptor (c-fms product) by cells at the human uteroplacental interface. Lab Invest 1993, 68:308-320

92. Hamilton GS, Lysiak JJ, Watson AJ, Lala PK: Effects of colony stimulating factor-1 on human extravillous trophoblast growth and invasion. J Endocrinol 1998, 159:69-77

93. Kliman HJ, Feinberg RF: Human trophoblast-extracellular matrix (ECM) interactions in vitro: ECM thickness modulates morphology and proteolytic activity. Proc Natl Acad Sci USA 1990, 87:30573061

94. Nasu K, Zhou Y, McMaster MT, Fisher SJ: Upregulation of human 
cytotrophoblast invasion by hepatocyte growth factor. J Reprod Fertil Suppl 2000, 55:73-80

95. Assali NS, Rauramo L, Petonen T: Measurement of uterine blood flow and uterine metabolism. VIII. Uterine and fetal blood flow and oxygen consumption in early human pregnancy. Am J Obstet Gynecol 1960, 79:86-98

96. Assali NS, Douglass RA Jr, Baird WW, Nicholson DB, Suyemoto R: Measurement of uterine blood flow and uterine metabolism. IV. Results in normal pregnancy. Am J Obstet Gynecol 1953, 66:248253

97. Romney SL, Metcalfe J, Reid DE, Burwell CS: Blood flow of the gravid uterus. Ann NY Acad Sci 1958, 75:762-769

98. Maini CL, Rosati P, Galli G, Bellati U, Bonetti MG, Moneta E: Noninvasive radioisotopic evaluation of placental blood flow. Gynecol Obstet Invest 1985, 19:196-206

99. Thaler I, Manor D, Itskovitz J, Rottem S, Levit N, Timor-Tritsch I, Brandes JM: Changes in uterine blood flow during human pregnancy. Am J Obstet Gynecol 1990, 162:121-125

100. Ueland K: Maternal cardiovascular dynamics. VII. Intrapartum blood volume changes. Am J Obstet Gynecol 1976, 126:671-677

101. Metcalfe J, Ueland K: Maternal cardiovascular adjustments to pregnancy. Prog Cardiovasc Dis 1974, 16:363-374

102. Ueland K, Metcalfe J: Circulatory changes in pregnancy. Clin Obstet Gynecol 1975, 18:41-50

103. Ziegler WF, Bernstein I, Badger G, Leavitt T, Cerrero ML: Regional hemodynamic adaptation during the menstrual cycle. Obstet Gynecol 1999, 94:695-699

104. Hansen V, Maigaard S, Allen J, Forman A: Effects of vasoactive intestinal polypeptide and substance $\mathrm{P}$ on human intramyometrial arteries and stem villous arteries in term pregnancy. Placenta 1988, 9:501-506

105. Skajaa K, Forman A, Andersson KE: Effects of magnesium on isolated human fetal and maternal uteroplacental vessels. Acta Physiol Scand 1990, 139:551-559

106. Cunningham FG, MacDonald PC, Gant NF, Leveno KJ, Gilstrap LCI, Hankins GDV, Clark SL: Williams Obstetrics, 20th ed. Stamford, CT, Appleton \& Lange, 1997

107. Wolff K, Nisell H, Modin A, Lundberg JM, Lunell NO, Lindblom B Contractile effects of endothelin 1 and endothelin 3 on myometrium and small intramyometrial arteries of pregnant women at term. Gynecol Obstet Invest 1993, 36:166-171

108. Fried G, Liu YA: Effects of endothelin, calcium channel blockade and EDRF inhibition on the contractility of human uteroplacental arteries. Acta Physiol Scand 1994, 151:477-484

109. Kublickiene KR, Wolff K, Kublickas M, Lindblom B, Lunell NO, Nisell $\mathrm{H}$ : Effects of isradipine on endothelin-induced constriction of myometrial arteries in normotensive pregnant women. Am J Hypertens 1994, 7:50S-55S

110. Petersen LK, Svane D, Uldbjerg N, Forman A: Effects of human relaxin on isolated rat and human myometrium and uteroplacental arteries. Obstet Gynecol 1991, 78:757-762

111. Neri I, Mazza V, Galassi MC, Volpe A, Facchinetti F: Effects of $\mathrm{L}$-arginine on utero-placental circulation in growth-retarded fetuses. Acta Obstet Gynecol Scand 1996, 75:208-212

112. Amit A, Thaler I, Paz Y, Itskovitz-Eldor J: The effect of a nitric oxide donor on Doppler flow velocity waveforms in the uterine artery during the first trimester of pregnancy. Ultrasound Obstet Gynecol 1998, 11:94-98

113. Grab D, Paulus WE, Erdmann M, Terinde R, Oberhoffer R, Lang D, Muche R, Kreienberg R: Effects of low-dose aspirin on uterine and fetal blood flow during pregnancy: results of a randomized, placebo-controlled, double-blind trial. Ultrasound Obstet Gynecol 2000, 15:19-27

114. Harrington K, Kurdi W, Aquilina J, England P, Campbell S: A prospective management study of slow-release aspirin in the palliation of uteroplacental insufficiency predicted by uterine artery Doppler at 20 weeks. Ultrasound Obstet Gynecol 2000, 15:13-18

115. Philipp K, Pateisky N, Endler M: Effects of smoking on uteroplacental blood flow. Gynecol Obstet Invest 1984, 17:179-182

116. Andersen KV, Hermann N: Placenta flow reduction in pregnant smokers. Acta Obstet Gynecol Scand 1984, 63:707-709

117. Lehtovirta P, Forss M: The acute effect of smoking on intervillous blood flow of the placenta. Br J Obstet Gynaecol 1978, 85:729-731
118. Galasko Gl: Cocaine, a risk factor for myocardial infarction. J Cardiovasc Risk 1997, 4:185-190

119. Pitts WR, Lange RA, Cigarroa JE, Hillis LD: Cocaine-induced myocardial ischemia and infarction: pathophysiology, recognition, and management. Prog Cardiovasc Dis 1997, 40:65-76

120. Hadeed AJ, Siegel SR: Maternal cocaine use during pregnancy: effect on the newborn infant. Pediatrics 1989, 84:205-210

121. Monga M, Chmielowiec S, Andres RL, Troyer LR, Parisi VM: Cocaine alters placental production of thromboxane and prostacyclin. Am $J$ Obstet Gynecol 1994, 171:965-969

122. Lavi E, Montone KT, Rorke LB, Kliman HJ: Fetal akinesia deformation sequence (Pena-Shokeir phenotype) associated with acquired intrauterine brain damage. Neurology 1991, 41:1467-1468

123. Chasnoff IJ, Burns KA, Burns WJ: Cocaine use in pregnancy: perinatal morbidity and mortality. Neurotoxicol Teratol 1987, 9:291-293

124. Norman B, Hansell RS, Evans MA: Pregnancy, abruptio placentae and cocaine. Indiana Med 1990, 83:634-639

125. Sturner WQ, Sweeney KG, Callery RT, Haley NR: Cocaine babies: the scourge of the '90s. J Forensic Sci 1991, 36:34-39

126. Holzman $\mathrm{C}$, Paneth N: Maternal cocaine use during pregnancy and perinatal outcomes. Epidemiol Rev 1994, 16:315-334

127. Longo LD: Maternal blood volume and cardiac output during pregnancy: a hypothesis of endocrinologic control. Am J Physiol 1983, 245:R270-R279

128. Bulmer JN: Immune aspects of pathology of the placental bed contributing to pregnancy pathology. Baillieres Clin Obstet Gynaecol 1992, 6:461-488

129. Zeeman GG, Dekker GA, van Geijn HP, Kraayenbrink AA: Endothelial function in normal and pre-eclamptic pregnancy: a hypothesis. Eur J Obstet Gynecol Reprod Biol 1992, 43:113-122

130. Redman CW, Sacks GP, Sargent IL: Preeclampsia: an excessive maternal inflammatory response to pregnancy. Am J Obstet Gynecol 1999, 180:499-506

131. Brown DW: Pre-eclampsia: a mistake of trophoblastic cells for tumour cells? Med Hypotheses 1999, 53:124-126

132. Widschwendter M, Schrocksnadel H, Mortl MG: Pre-eclampsia: a disorder of placental mitochondria? Mol Med Today 1998, 4:286291

133. van Beck E, Peeters LL: Pathogenesis of preeclampsia: a comprehensive model. Obstet Gynecol Surv 1998, 53:233-239

134. Dekker GA, Robillard PY, Hulsey TC: Immune maladaptation in the etiology of preeclampsia: a review of corroborative epidemiologic studies. Obstet Gynecol Surv 1998, 53:377-382

135. Dekker GA, Sibai BM: Etiology and pathogenesis of preeclampsia: current concepts. Am J Obstet Gynecol 1998, 179:1359-1375

136. Walsh SW: Preeclampsia: an imbalance in placental prostacyclin and thromboxane production. Am J Obstet Gynecol 1985, 152:335340

137. Hardy TJ, Williams PB: Pre-eclampsia: a hypothesis for its etiology Med Hypotheses 1988, 27:157-162

138. Salas SP: What causes pre-eclampsia? Best Pract Res Clin Obstet Gynaecol 1999, 13:41-57

139. Sladek SM, Magness RR, Conrad KP: Nitric oxide and pregnancy. Am J Physiol 1997, 272:R441-R463

140. Vinatier D, Monnier JC: Pre-eclampsia: physiology and immunological aspects. Eur J Obstet Gynecol Reprod Biol 1995, 61:85-97

141. Soma H, Yoshida K, Mukaida T, Tabuchi Y: Morphologic changes in the hypertensive placenta. Contrib Gynecol Obstet 1982, 9:58-75

142. Wynn RM: The placenta in preeclampsia. Obstet Gynecol Annu 1977, 6:191-196

143. Khong TY, Sawyer $\mathbb{H}$ : The human placental bed in health and disease. Reprod Fertil Dev 1991, 3:373-377

144. Toppozada MK: Role of prostaglandins in pre-eclampsia. Acta Obstet Gynecol Scand 1990, 69:375-377

145. Rodrigues FA, Hofmeyr GJ, Sonnendecker EW, Atkinson PM: Hypothesis: a central role for platelet activating factor in the pathogenesis of pre-eclampsia. Med Hypotheses 1989, 28:285-286

146. Brown MA, Wang J, Whitworth JA: The renin-angiotensin-aldosterone system in pre-eclampsia. Clin Exp Hypertens 1997, 19:713726

147. Feinberg RF, Kliman HJ, Cohen AW: Preeclampsia, trisomy 13, and the placental bed. Obstet Gynecol 1991, 78:505-508 
148. Adamsons K, Wallach RC: Single cause for initiation of labor and toxemia: a hypothesis. Am J Perinatol 1989, 6:133-137

149. Cockell AP, Poston L: Flow-mediated vasodilatation is enhanced in normal pregnancy but reduced in preeclampsia. Hypertension 1997, 30:247-251

150. Pijnenborg R, Anthony J, Davey DA, Rees A, Tiltman A, Vercruysse $L$, van Assche A: Placental bed spiral arteries in the hypertensive disorders of pregnancy. Br J Obstet Gynaecol 1991, 98:648-655

151. Sheppard BL, Bonnar J: An ultrastructural study of utero-placental spiral arteries in hypertensive and normotensive pregnancy and fetal growth retardation. Br J Obstet Gynaecol 1981, 88:695-705

152. Sheppard BL, Bonnar J: The ultrastructure of the arterial supply of the human placenta in pregnancy complicated by fetal growth retardation. Br J Obstet Gynaecol 1976, 83:948-959

153. Gerretsen G, Huisjes HJ, Hardonk MJ, Elema JD: Trophoblast alterations in the placental bed in relation to physiological changes in spiral arteries. Br J Obstet Gynaecol 1983, 90:34-39
154. Nakabayashi M, Yamamoto S, Suzuki K: Analysis of thrombomodulin gene polymorphism in women with severe early-onset preeclampsia. Semin Thromb Hemost 1999, 25:473-479

155. Arkwright PD, Rademacher TW, Dwek RA, Redman CW: Preeclampsia is associated with an increase in trophoblast glycogen content and glycogen synthase activity, similar to that found in hydatidiform moles. J Clin Invest 1993, 91:2744-2753

156. Christiane $Y$, Aghayan M, Emonard H, Lallemand A, Mahieu $P$, Foidart JM: Galactose alpha 1-3 galactose and anti-alpha galactose antibody in normal and pathological pregnancies. Placenta 1992 13:475-487

157. Sheppard BL, Bonnar J: Uteroplacental hemostasis in intrauterine fetal growth retardation. Semin Thromb Hemost 1999, 25:443-446

158. Gerretsen G, Huisjes HJ, Elema JD: Morphological changes of the spiral arteries in the placental bed in relation to pre-eclampsia and fetal growth retardation. Br J Obstet Gynaecol 1981, 88:876-881

159. Naeye RL: Placental infarction leading to fetal or neonatal death: a prospective study. Obstet Gynecol 1977, 50:583-588 